\title{
Electrochemical Stability and Ambipolar Charge Transport in Diketopyrrolopyrrole-Based Organic Materials
}

Suman Ray, ${ }^{\dagger, \perp}$ Julianna Panidi, $^{\ddagger}$ Tushita Mukhopadhyay, ${ }^{\dagger}$ Ulrike Salzner, ${ }^{\|}$Thomas D. Anthopoulos, ${ }^{\ddagger} \S_{\odot}$ and Satish Patil ${ }^{*}, \oplus$

\author{
${ }^{\dagger}$ Solid State and Structural Chemistry Unit, Indian Institute of Science, Bangalore 560012, India \\ ${ }^{\ddagger}$ Department of Physics and Centre for Plastic Electronics, Blackett Laboratory, Imperial College London, London SW7 2AZ, \\ United Kingdom \\ ${ }^{\S}$ King Abdullah University of Science and Technology (KAUST), Division of Physical Sciences and Engineering, Thuwal \\ 23955-6900, Saudi Arabia \\ "Department of Chemistry, Bilkent University, 06800 Ankara, Turkey \\ ${ }^{\perp}$ Department of Chemistry, Presidency University, 86/1 College Street, Kolkata 700073, India
}

Supporting Information

ABSTRACT: An important strategy for realizing flexible complementary circuits with organic semiconductors is to achieve balanced ambipolar charge transport properties with reduced anisotropy. Here, we present a series of star-shaped diketopyrrolopyrrole (DPP)-based organic materials synthesized for improved intermolecular charge transport while retaining the ambipolar charge transport properties of their linear counterparts. Steady-state UV-visible spectroscopic studies confirm that the oligomers are highly aggregated in the thin film as evidenced from appearance of prominent vibronic features and red-shifted absorption bands. Ambipolar transport properties of these materials were verified in organic field-effect transistors (OFETs). The results show that the star-shaped DPP systems have the potential to outperform their linear counterparts in devices.

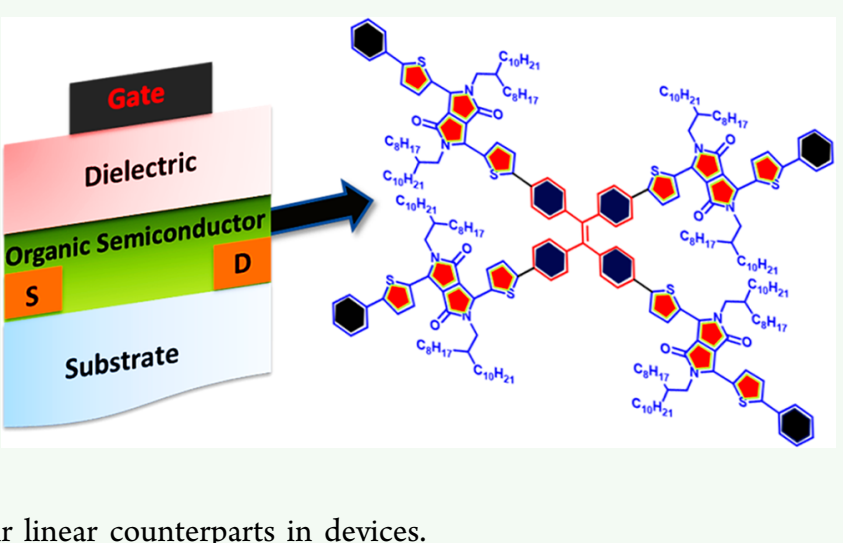

KEYWORDS: diketopyrrolopyrrole, ambipolar charge transport, star-shaped molecule, field-effect transistor, tetraphenylethylene

\section{INTRODUCTION}

Air-stable organic semiconductors with balanced hole and electron mobilities have potential applications in complementary circuits and displays. ${ }^{1}$ To date, great advances have been made in the performance of the $\mathrm{p}$-channel ${ }^{2-6}$ organic fieldeffect transistors (OFETs) with hole mobilities as high as 6$23 \mathrm{~cm}^{2} \mathrm{~V}^{-1} \mathrm{~s}^{-1}$. However, fabrication of air stable ambipolar OFETs with balanced electron/hole mobilities is challenging because (i) n-doped organic semiconductors are extremely prone to air oxidation, (ii) mismatch of energy offset between the frontier molecular orbitals of the semiconductors and the Fermi level of commonly used electrodes ( $\mathrm{Au}, \mathrm{Ag}$ etc.), (iii) the lowest unoccupied molecular orbitals (LUMOs) must remain delocalized with the minimum number of traps to facilitate electron hopping. ${ }^{7-10}$ However, a primary requisite of balanced hole and electron mobility with air stability is highly desirable in bipolar electronic devices such as low power complementary integrated circuits, ${ }^{11}$ photodetectors, ${ }^{12}$ and organic solar cells. ${ }^{13,14}$ To overcome these issues, several research groups have developed donor-acceptor based conjugated polymers to improve stability and electron mobility. For example, $\mathrm{Li}$ et al. observed unipolar electron mobility of $6.3 \mathrm{~cm}^{2} \mathrm{~V}^{-1} \mathrm{~s}^{-1}$ on coupling pyridine to DPP to achieve organized self-assembly. ${ }^{15}$ Recently, ambipolar charge transport has been reported for as-cast and thermally annealed OFETs and organic logic inverters made from solutionprocessed DPP-based small molecules. ${ }^{16,17} \mathrm{Kim}$ et al. used DPP as an acceptor and dithienosilole-core donor, achieving ambipolar transport characteristics. ${ }^{18}$ Wang et al. achieved a high-performance ambipolar small molecule semiconductor by improving the crystallinity and morphological properties by coupling DPP with rhodanine. ${ }^{19}$ In our group, we rationally designed and synthesized DPP-DPP-based copolymers and oligomers which exhibit bandlike and ambipolar charge transport properties. ${ }^{20,21}$ In addition, ambipolar charge transport was realized by electrode design in rubrene-based organic semiconductors resulting in hole and electron mobilities of $\sim 22$ and $\sim 5.0 \mathrm{~cm}^{2} \mathrm{~V}^{-1} \mathrm{~s}^{-1}$, respectively. ${ }^{22,23}$ However, these studies have been carried out on $\pi$-conjugated oligomers and polymers possessing linear and one-dimensional chains.

Received: June 21, 2019

Accepted: September 2, 2019

Published: September 2, 2019 


\section{Scheme 1. Synthesis of TPE-DPP-Based Oligomers}
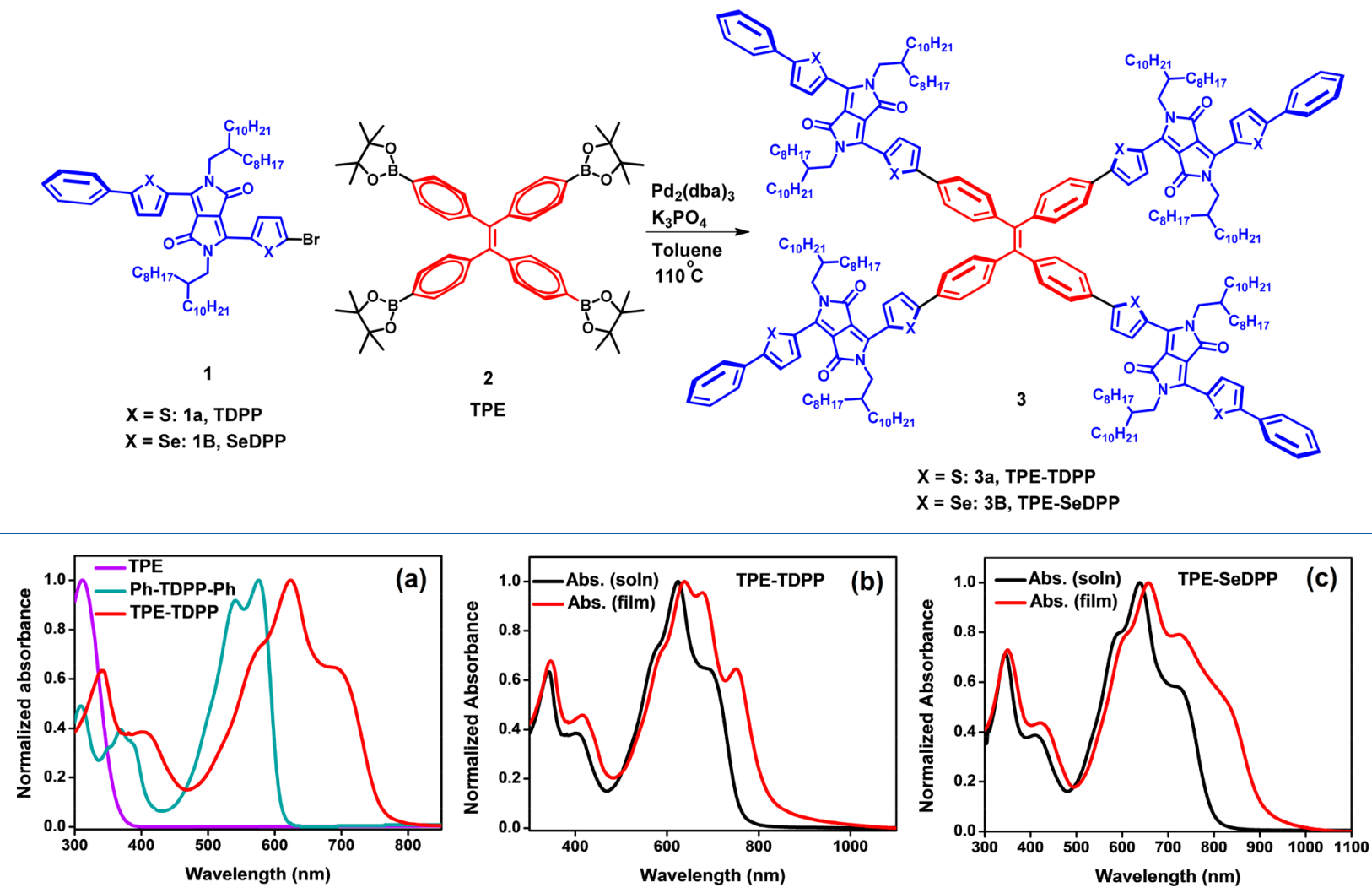

Figure 1. (a) Comparison of absorption spectra of TPE, Ph-TDPP-Ph, and TPE-TDPP; (b,c) normalized UV-vis/near-IR absorption spectra of TPE-TDPP and TPE-SeDPP.

Although linear molecules show efficient charge transport along the $\pi$-conjugated backbone, most of the linear molecules exhibit limited lateral overlap in both the face-on and edge-on packing arrangement. ${ }^{24,25}$ The rate of charge transport in the direction of the stacks and along the alkyl chain interdigitation is low. This results in anisotropic carrier transport. ${ }^{26,27}$ Since the anisotropy of the carrier transport stems from the linearity of the semiconductor systems, design of star-shaped ${ }^{28-31}$ systems with conjugation in two perpendicular directions can be expected to give a possible solution to the problem. Kirchmeyer et al. proposed that star-shaped molecules can arrange themselves parallel to a surface and with respect to one another, forming 2D lamellae which are beneficial for charge transport. $^{32}$ They also possess sufficiently high glass transition temperatures which render their processability at elevated temperatures. ${ }^{33}$ However, despite all these fascinating properties, reports of ambipolar OFETs fabricated from star-shaped organic materials are rare and exhibit poor performance. $^{30,32-39}$ For example, Zhu et al. used oligothiophenefunctionalized truxene as an active layer for OFET achieving mobility 1 order of magnitude higher $\left(0.001 \mathrm{~cm}^{2} \mathrm{~V}^{-1} \mathrm{~s}^{-1}\right)$ than Kirchmeyer et al. ${ }^{30}$ Chen et al. reported diketopyrrolopyrrole based star-shaped molecules with hole mobility up to 0.0026 $\mathrm{cm}^{2} \mathrm{~V}^{-1} \mathrm{~s}^{-1}$. ${ }^{34}$ Very recently, Heeney and co-workers showed an improvement of carrier transport mobility over the previously reported star-shaped molecules in benzodithiophene-diketopyrrolopyrrole oligomer with p-type mobility of $0.022 \mathrm{~cm}^{2} \mathrm{~V}^{-1} \mathrm{~s}^{-1}$. 35

Tetraphenylethylene (TPE) possesses a propeller-like starburst molecular structure with quasi-3D disposition of the phenyl rings. ${ }^{36,39,40}$ Therefore, unlike the fully 3D geometries which discontinue the electronic communication between the spokes, the TPE-core maintains some extent of conjugation of the arms through the core. This decreases highest occupied molecular orbital-lowest unoccupied molecular orbital (HOMO-LUMO) energy gaps and enhances the charge transport and photovoltaic efficiencies. ${ }^{36}$ Considering these properties of the TPE core, we synthesized star-shaped $\mathrm{D}-\mathrm{A}$ type $\pi$-conjugated molecules by coupling the TPE core with DPP (acceptor, A) flanked on both sides by thiophene (TDPP) and selenophene (SeDPP) donors (D) and investigated their charge transport properties in OFETs device geometry. The OFET device shows the characteristic of ambipolar charge transport with a pronounced increase in the channel current at low $V_{\mathrm{GS}}$ and high $V_{\mathrm{DS}}$, particularly for the electron accumulation mode. This work shows the importance of judicious tailoring and design of star-shaped molecules to achieve ambipolar charge transport properties similar to those of their linear ${ }^{41}$ analogues. The charge carrier mobilities are moderately high as compared to the previously reported values on star-shaped molecules.

\section{RESULTS AND DISCUSSION}

2.1. Synthesis. The synthetic scheme for the compounds TPE-TDPP (3a) and TPE-SeDPP (3b) is shown in Scheme 1. The TPE core was functionalized with DPP derivatives endcapped with phenyl rings. The TPE-DPP-based oligomers were synthesized via a $\operatorname{Pd}_{2}(\mathrm{dba})_{3}$ catalyzed Suzuki coupling reaction involving the tetra-boronic ester of TPE and the monobromoderivatives of benzene end-capped DPP. The detailed synthetic 

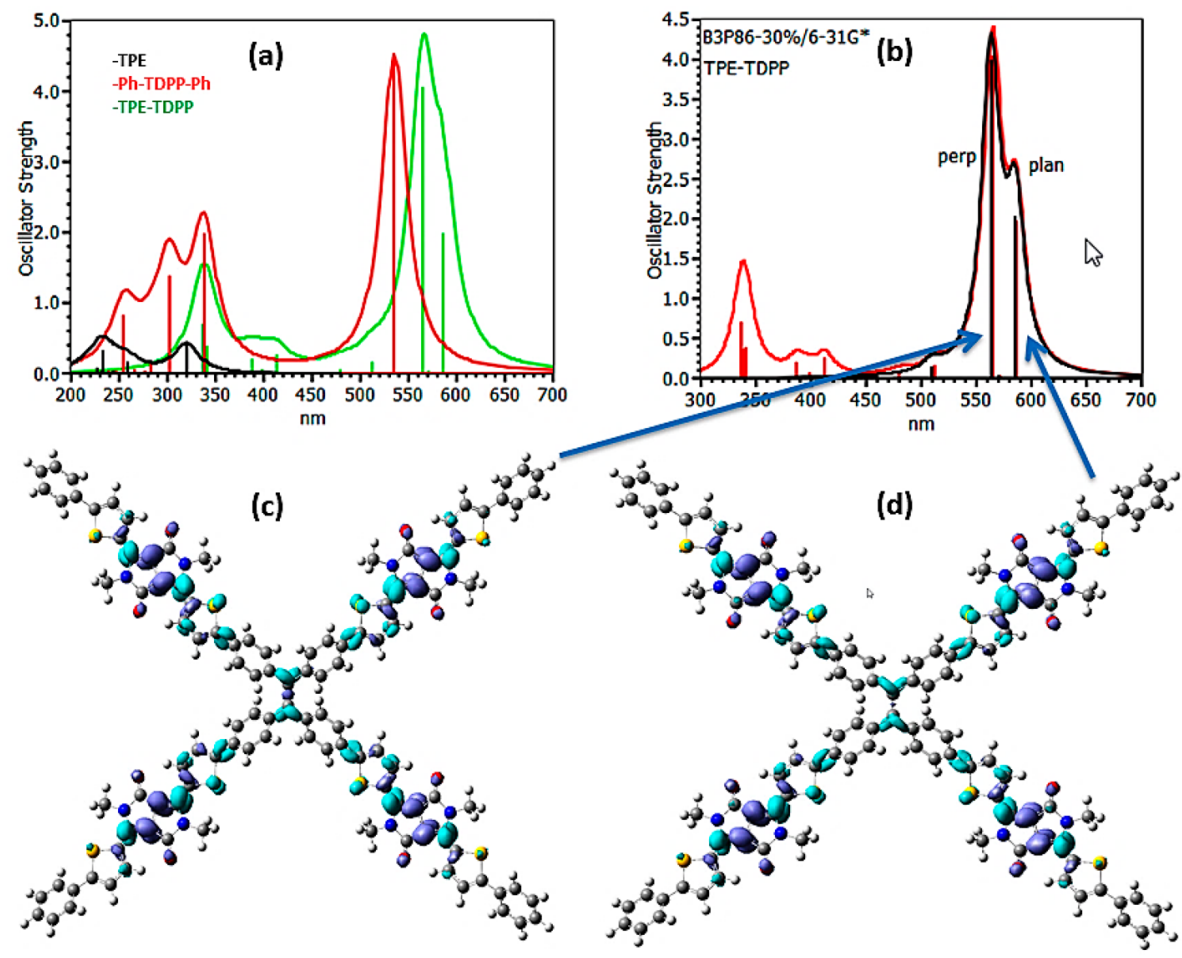

Figure 2. (a) Comparison of absorption spectra of TPE-TDPP, TDPP, and TPE fragments; (b) TPE-TDPP with almost planar (red) and almost perpendicular (black) conformations; (c) density differences between ground and first excited states; and (d) density differences between ground and second excited states of TPE-TDPP.

procedures are described in the Supporting Information. The structural characterization of the oligomers was performed by ${ }^{1} \mathrm{H}$ and ${ }^{13} \mathrm{C}$ NMR and MALDI MS (Supporting Information).

2.2. Optical and Electrochemical Properties. UVvisible studies were carried out to probe the aggregation and excitonic interchain coupling in the solution phase. A comparison of absorption spectra of the TPE core, PhTDPP-Ph and TPE-TDPP shown in Figure 1a, reveals that the TPE-TDPP absorption is red-shifted compared to that of PhTDPP-Ph, implying electronic coupling between the TDPP arms through the TPE core. The shapes of the solution phase absorption spectra of both TPE-TDPP and TPE-SeDPP are strikingly similar. The absorption maximum was observed at $623 \mathrm{~nm}$ with a broad distributed tail at 573 and $693 \mathrm{~nm}$ for TPE-TDPP, whereas for TPE-SeDPP the absorption maximum appears at $638 \mathrm{~nm}$ with two shoulders at 588 and 725 $\mathrm{nm}$ (Figure 1b,c). These observations are reproduced quantitatively with TDDFT calculations. Theory reveals that there are two conformers (Figure S7) that differ in the relative signs of the dihedral angles between ethylene and phenyl groups of TPE and between phenyl and thienyl (selenyl) groups of TDPP and SeDPP. The energy difference between these conformers is only $0.2 \mathrm{kcal} / \mathrm{mol}$. In solution, there should therefore exist a mixture of all possible conformers arising from combinations of twisting directions of the arms. As shown in Figure 2b (and Figure S8a), the twist angle has practically no influence on the spectra. Compared to $\mathrm{Ph}$ TDPP-Ph or Ph-SeDPP-Ph fragments (Figure 2a), coupling with TPE leads to a splitting of the low energy absorption into two electronic transitions at 587 and $565 \mathrm{~nm}$ for TPE-TDPP and at 598 and $577 \mathrm{~nm}$ for TPE-SeDPP. As shown in Figure 2c,d (and Figure S8b,c), both low lying excited states arise from the same electronic transitions on the arms with slightly different involvement of TPE.

The red shifts compared to Ph-TDPP-Ph or Ph-SeDPP-Ph amount to 51 and $52 \mathrm{~nm}$, respectively. The oscillator strengths of Ph-TDPP-Ph or Ph-SeDPP-Ph in Figure 2a were multiplied by four to compare with TPE-TDPP and TPE-SeDPP which contain four TDPP (SeDPP) units. The oscillator strength in the low-energy region (considering both close lying peaks) is increased in TPE-TDPP by $33 \%$ compared to that of four units of Ph-TDPP-Ph, revealing a significant effect of the TPE core on the absorption intensity. Density difference plots between the ground and excited states (Figure $2 \mathrm{c}$,d and Figure S8b,c) and analysis of the charges in the ground and excited states reveal that all transitions have $\pi-\pi^{*}$ character with charge transfer to and from DPP never exceeding 0.03 electrons. The calculated dihedral angles are $47^{\circ}$ between the ethylene plane and the phenyl rings and $23^{\circ}$ between the phenyl and the thiophene (selenophene) rings. Rotation of phenyl and thienyl in the same direction leads to arms being twisted by $70^{\circ}$ with respect to the ethylene plane. Rotation in the opposite direction leads to an almost planar molecular shape with arms being twisted by only $21^{\circ}$ degrees with respect to the ethylene plane. The more planar conformers might be prevalent in the solid state due to better $\pi$-stacking ability.

In the experimental spectra, the shoulders at 693 (TPETDPP) and $725 \mathrm{~nm}$ (TPE-SeDPP) on the low energy side are due to preorganization of the oligomers even in dilute solution. Both TPE-TDPP and TPE-SeDPP exhibit well-defined vibronic features in solution and thin films which implies the presence of aggregates. Vibronic features arise as a result of relative predominance of $\mathrm{J}$ - and $\mathrm{H}$-aggregates in thin film. If there is rapid conformational switching, the vibronic features tend to disappear. Formation of aggregates in the solid-state or 
Table 1. Electrochemical Properties of the Star-Shaped Molecules

\begin{tabular}{|c|c|c|c|c|c|c|c|}
\hline \multirow[b]{2}{*}{ molecules } & \multicolumn{2}{|c|}{ optical properties } & \multicolumn{3}{|c|}{ electrochemical properties ${ }^{b}$} & \multicolumn{2}{|c|}{ UPS } \\
\hline & $\lambda_{\max }(\mathrm{nm})(\mathrm{abs})$. & $\Delta E_{\mathrm{g}}^{\mathrm{opt}}(\mathrm{eV})^{a}$ & $E_{\text {Номо }}(\mathrm{eV})$ & $E_{\text {LUMO }}(\mathrm{eV})$ & $\Delta E_{\mathrm{g}}^{\mathrm{ec}}(\mathrm{eV})$ & $E_{\text {Номо }}(\mathrm{eV})$ & $E_{\text {LUMO }}(\mathrm{eV})^{c}$ \\
\hline TPE-TDPP & 623 & 1.51 & -5.22 & -3.73 & 1.49 & -5.22 & -3.71 \\
\hline TPE-SeDPP & 638 & 1.40 & -5.01 & -3.69 & 1.32 & -4.99 & -3.59 \\
\hline
\end{tabular}

${ }^{a}$ Band gap calculated from thin film absorption data. ${ }^{b} \mathrm{Cyclic}$ voltammetric analyses were carried out with reference to the $\mathrm{Ag} / \mathrm{AgCl}$ electrode and $\mathrm{Fc} / \mathrm{Fc}^{+}$couple as standard. HOMO and LUMO energy levels were calculated according to the formula: $E_{\mathrm{HOMO}}=-\left(E_{\mathrm{ox}}+4.52\right) \mathrm{eV}$ and $E_{\mathrm{LUMO}}=$ $-\left(E_{\text {red }}+4.52\right) \mathrm{eV} .{ }^{c}$ Extracted from ultraviolet photoemission spectroscopy (UPS) data coupled with thin film absorption data.
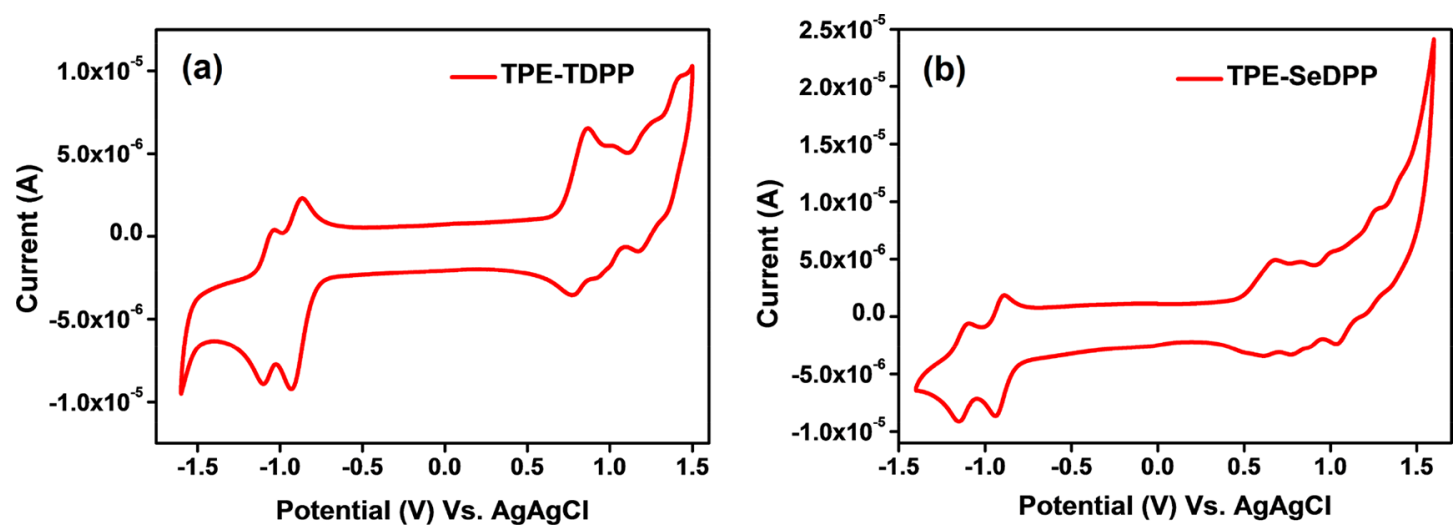

Figure 3. Cyclic voltammograms of (a) TPE-TDPP and (b) TPE-SeDPP.
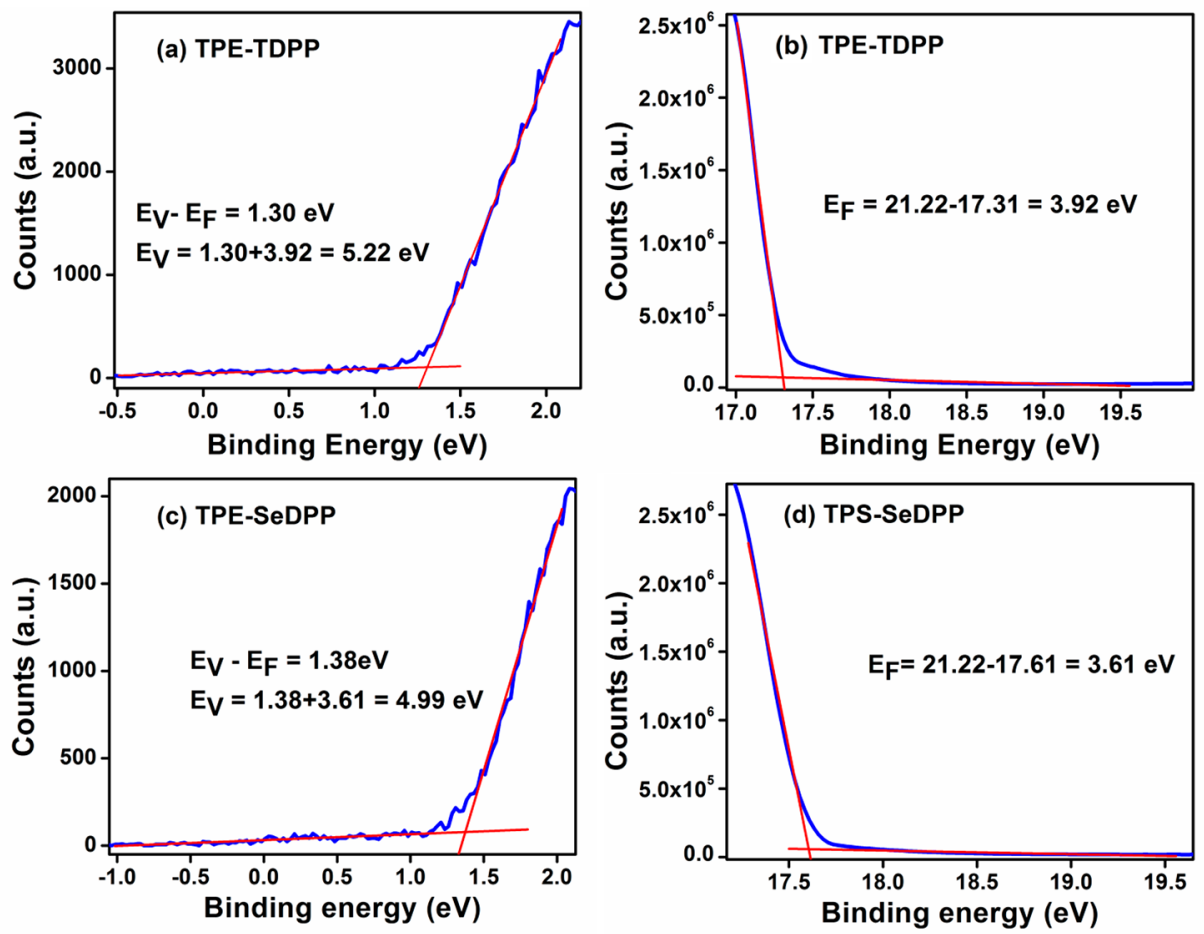

Figure 4. Ultraviolet photoemission spectroscopy (UPS) (a and c) extraction of Fermi levels and (b and d) valence band energies.

in preorganized state in solution result in the splitting of the excited state depending on the degree of solid-state intermolecular interactions. This splitting breaks the continuum in the band resulting in quantum mechanically allowed and/or disallowed transitions which results in vibronic features. ${ }^{42-44}$

In the thin film on quartz substrates, the absorption spectra of both compounds show substantial bathochromic shifts compared to the solution phase, indicating the formation of J- type aggregates. This change is attributed to the increased interchain interactions, backbone planarity, and molecular ordering. For TPE-TDPP, on switching from solution to the thin film, the main absorption band at 623 is split into two distinguished peaks. However, for both TPE-TDPP and TPESeDPP, the intensity of the lowest energy peak, commonly referred to as the $0-0$ vibration, enhances in the solid state. This indicates the formation of J-type aggregates. ${ }^{45}$ However, the spectrum of TPE-SeDPP is broader compared to that of 


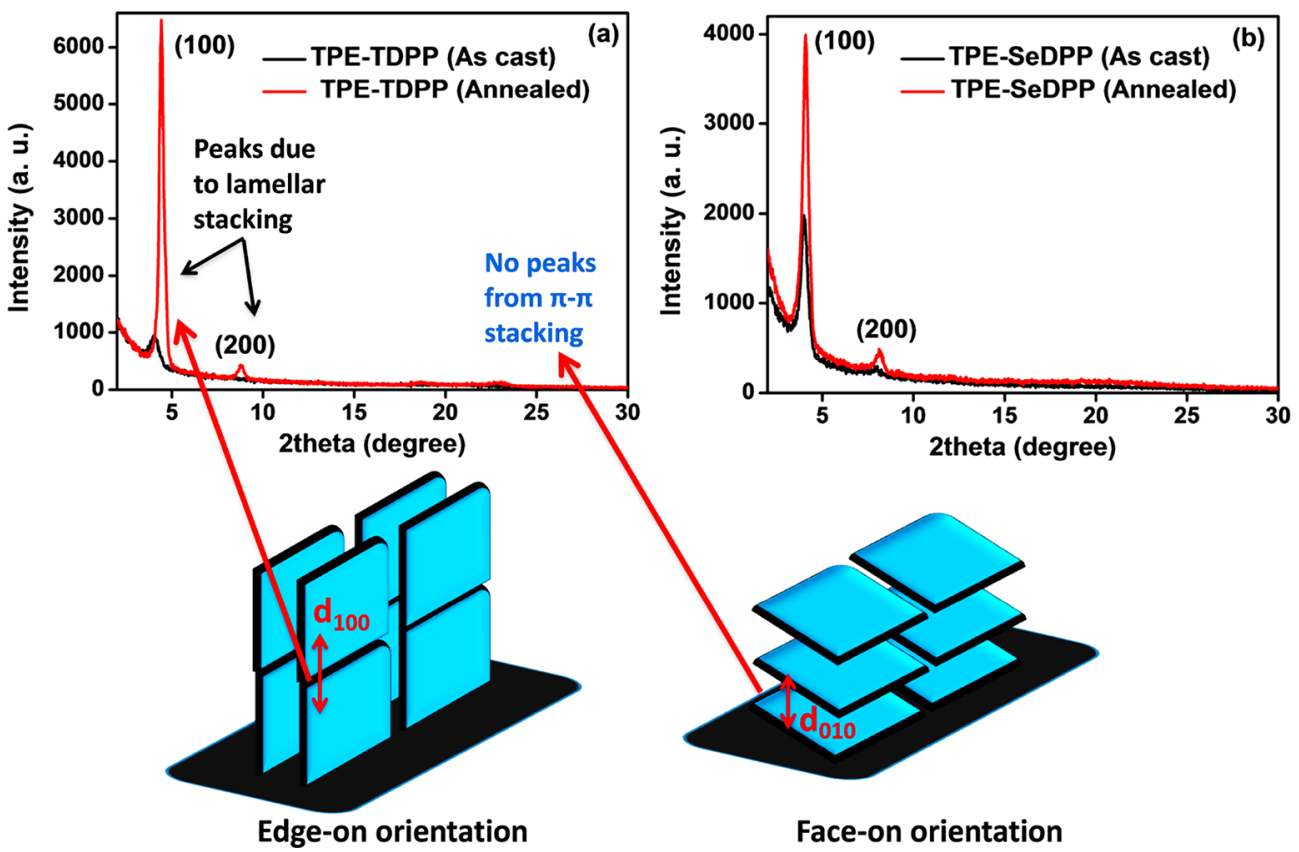

Figure 5. Thin film X-ray diffractograms of (a) TPE-TDPP and (b) TPE-SeDPP oligomers deposited on Si substrates.

Table 2. Lamellar d-Spacing from Thin-Film X-ray Diffraction Analysis

\begin{tabular}{cccccc} 
& \multicolumn{3}{c}{ as cast film } & & \multicolumn{2}{c}{ annealed film } \\
\cline { 2 - 3 } \cline { 5 - 6 } molecules & $2 \theta_{100}\left(\mathrm{~d}_{100}\right)$ & $2 \theta_{200}\left(\mathrm{~d}_{200}\right)$ & & $2 \theta_{100}\left(\mathrm{~d}_{100}\right)$ & $2 \theta_{200}\left(\mathrm{~d}_{200}\right)$ \\
TPE-TDPP & $4.06(2.17 \mathrm{~nm})$ & & & $4.41(2.00 \mathrm{~nm})$ & $8.80(1.00 \mathrm{~nm})$ \\
TPE-SeDPP & $4.02(2.19 \mathrm{~nm})$ & $8.01(11.00 \mathrm{~nm})$ & & $4.08(2.16 \mathrm{~nm})$ & $8.17(1.08 \mathrm{~nm})$ \\
\hline
\end{tabular}

TPE-TDPP. Because interchain association via nonbonding forces is stronger with Se than with $S$, the thin film absorption spectra of TPE-TDPP and TPE-SeDPP are different. ${ }^{46,47}$ To further investigate the effect of aggregation on optical properties, we have recorded optical properties of TPETDPP in a THF/water mixture. The absorption spectra exhibit a bathochromic shift after addition of water implying the formation of J-aggregates. Long-wavelength tails were observed in the absorption profile due to scattering from precipitated particles present in solution (see Figure S1). The optical gaps $\left(E_{\mathrm{g}}\right)$ extracted from the absorption edges of the thin film spectra are 1.51 and $1.40 \mathrm{eV}$ for TPE-TDPP and TPE-SeDPP, respectively (Table 1 ). There is a very good match between the optical and the electrochemical gaps. The optical gap of TPESeDPP is smaller than that of TPE-TDPP due to the lower ionization potential of Se. The molar extinction coefficients $(\varepsilon)$ measured in solution phase by UV-visible spectroscopy reveals that the Se-containing compound has a higher value of $\varepsilon$ (see Figure S2).

The electrochemical properties of oligomers were investigated by cyclic voltammetry $(\mathrm{CV})$. Both oligomers reveal reversible two-electron reductive cycles as well as reversible oxidation processes (Figure 3) as evident from the CV analysis of the oligomers in dichloromethane solution containing $n$ $\mathrm{Bu}_{4} \mathrm{NPF}_{6}$ as the supporting electrolyte.

From the CV plot, oxidation onset potentials of 0.70 (TPETDPP) and $0.49 \mathrm{~V}$ (TPE-SeDPP), and the reduction onset potentials of -0.79 (TPE-TDPP) and $-0.83 \mathrm{~V}$ (TPE-SeDPP), respectively, versus $\mathrm{Ag} / \mathrm{AgCl}$ electrode were estimated. The HOMO and LUMO energies were extracted by calibrating their first oxidation and reduction onset potentials (vs $\mathrm{Ag}$ /
$\mathrm{AgCl})$ to the ferrocene/ferrocenium $\left(\mathrm{Fc} / \mathrm{Fc}^{+}\right)$redox couple potential (measured as $0.28 \mathrm{~V}$ vs $\mathrm{Ag} / \mathrm{AgCl}$ ) and using the literature value of the ionization potential of the ferrocene. The HOMO and LUMO energy levels and the electrochemical band gap determined from the onset of the first oxidation and reduction peaks are summarized in Table 1 . The stability of redox properties of TPE-TDPP and TPE-SeTDPP were analyzed by $\mathrm{CV}$, and we see no evidence of loss in the redox properties of both the materials with multiple scans ${ }^{33}$ (Figure S3). The electrochemical data indicates that the redox states of the oligomers are stable at ambient conditions. The low-lying LUMO levels of the molecules enable facile electron injection, which is important for developing $\mathrm{n}$-channel and/or ambipolar OFETs.

2.3. Ultraviolet Photoemission Spectroscopy (UPS) Measurement. The ionization energies of the oligomers were further extracted from the UPS studies as shown in Figure 4. The positions of the HOMO energy levels obtained from UPS measurements are in good agreement with the values obtained from electrochemical measurement. The values of the Fermi energy levels of TPE-TDPP and TPE-SeDPP extracted from UPS measurement are 3.92 and $3.61 \mathrm{eV}$, respectively, and the corresponding HOMO energies are 5.23 and $4.99 \mathrm{eV}$. The relatively large differences between the HOMO levels and Fermi levels of the oligomers indicate the presence of low lying HOMOs for both the oligomers. Moreover, the HOMO energies are very close to the Fermi level of Au electrode (5.1 $\mathrm{eV})$, which leads to low hole injection barriers.

2.4. Thin-Film X-ray Diffraction Measurements. Thinfilm X-ray diffraction measurements have been carried out to evaluate the degree of crystallinity in the thin films of the TPE- 
DPP based polymers. The as-cast film of TPE-TDPP shows one order of diffraction planes as is evident from evolution of only (100) peak, whereas TPE-SeDPP exhibits two orders of crystallinity as both (100) and (200) diffraction peaks are seen (Figure 5). The corresponding lamellar "d" spacings are estimated from the (100) diffraction peaks in the out of plane direction using the Bragg's law (Table 2). ${ }^{47}$ As expected, the intensity of (100) peak of TPE-SeDPP is greater than that of TPE-TDPP in as cast film suggesting greater population of highly oriented aggregates and hence an enhanced crystallinity and microstructural ordering in the case of TPE-SeDPP oligomers. This can be attributed to the better interchain association via stronger nonbonding forces in TPE-SeDPP compared to TPE-TDPP, since selenophene is more polarizable than sulfur. ${ }^{47,48}$ Notably, no $\pi-\pi$ stacking diffraction peaks were detected. ${ }^{49,50}$ This is indicative of prominent edgeon chain orientation of the crystallites on the substrate. Upon annealing at $100{ }^{\circ} \mathrm{C}$, in the thin film of TPE-TDPP, the second order (200) peak becomes prominent. The intensity of first order diffraction peaks are increased, implying an increase in the population of ordered crystallites in the thin film, upon annealing for both the oligomers. Thus, the crystallinity is enhanced and the range of ordering is increased due to thermal annealing.

The lamellar spacing values decrease by $0.17 \mathrm{~nm}$ for TPETDPP and by $0.03 \mathrm{~nm}$ for TPE-SeDPP after annealing at 100 ${ }^{\circ} \mathrm{C}$, suggesting a closer association of the lamellae. Although the as-cast film TPE-SeDPP shows greater crystallinity than TPE-TDPP, after annealing, the (100) peak of TPE-TDPP exhibits a remarkable enhancement in intensity whereas that of TPE-SeDPP shows only a 2 -fold increase. This atypical behavior can be rationalized by the larger radius of selenium as compared to that of sulfur. ${ }^{47,48}$ It is well-known that the shorter the distance between the oligomer backbones, the stronger is the interaction and the greater is the extent of solidstate packing and hence the crystallinity. It can be envisaged that during the annealing process, TPE-TDPP with a very high degree of freedom, reorganizes itself into a well-aligned and long-range ordered state. ${ }^{31}$ However, the degree of reorganization of TPE-SeDPP to gain a well-organized state is restricted by the larger size of the selenium. ${ }^{47,48}$ The moderately small lamellar d-spacing implies that the chains are interdigitated favorably or tilted out of the $\pi$-conjugated skeleton, establishing better interchain interdigitation, ensuring better donoracceptor van der Waals interactions, and enhancing charge carrier mobility.

2.5. Organic Field Effect Transistors (OFETs). Organic field effect transistors were fabricated to evaluate the charge carrier mobilities of TPE-TDPP and TPE-SeDPP films. OFETs with gold source-drain electrodes were used to evaluate the hole mobilities, while a bilayer electrode composed of gold/aluminum was employed to extract electron mobilities. The selection of appropriate metals for the sourcedrain electrodes is critical, since there should be minimum energy offset between the energy level of the semiconductor and the work function of the metal. Charge injection/ extraction is affected by the metal selection of the devices and this has an attribute to the charge carrier mobility and the contact resistance. Since the HOMO levels of both materials are around $\sim 5 \mathrm{eV}$ (TPE-TDPP, $-5.22 \mathrm{eV}$; TPE-SeDPP, $\sim-5.01 \mathrm{eV}$ ) gold source-drain electrode for hole extraction, whereas since their LUMO level are around $\sim 3.7 \mathrm{eV}$ (TPETDPP, $-3.73 \mathrm{eV}$; TPE-SeDPP, $\sim 3.69 \mathrm{eV}$ ) a bilayer of gold/ aluminum is preferable for electron extraction. Figures 6 and 7 show the transfer characteristics $\left(I_{\mathrm{D}}\right.$ vs $\left.V_{\mathrm{G}}\right)$ of the TPE-TDPP
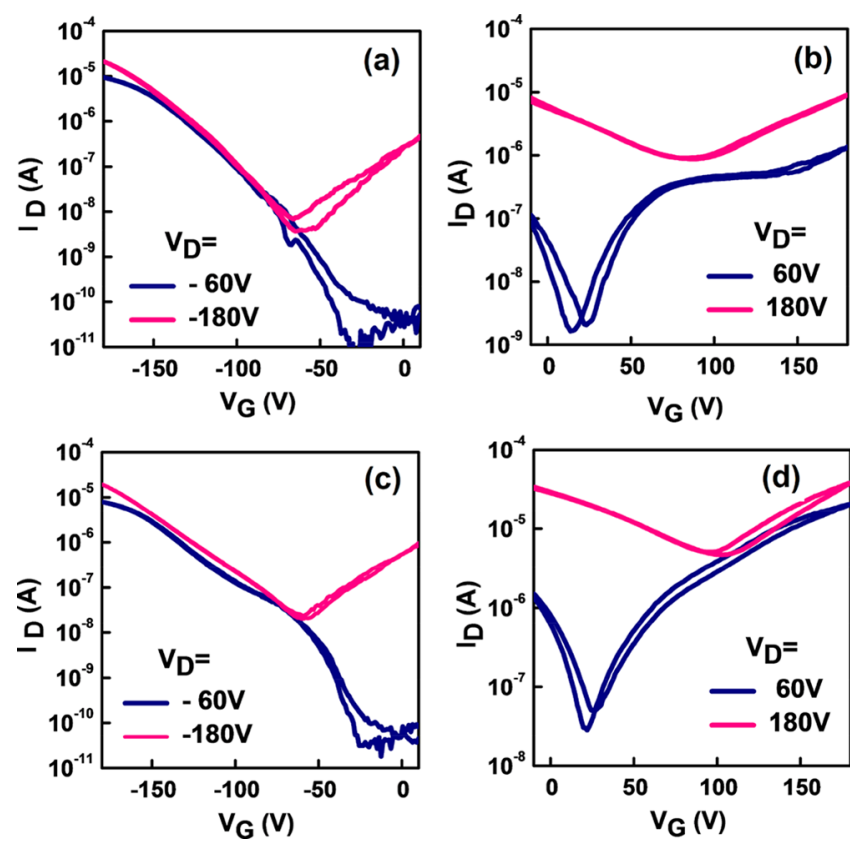

Figure 6. Transfer characteristics for TPE-TDPP oligomer when annealed at $50{ }^{\circ} \mathrm{C}$ (a and b) and at $100{ }^{\circ} \mathrm{C}$ (c and d). BC-TG TFTs with $\mathrm{Au}$ source-drain electrodes were used for holes (a and $\mathrm{c}$ ) and where a bilayer of $\mathrm{Au} / \mathrm{Al}$ was used for the electron charge carriers $(\mathrm{b}$ and $\mathrm{d}$ ).
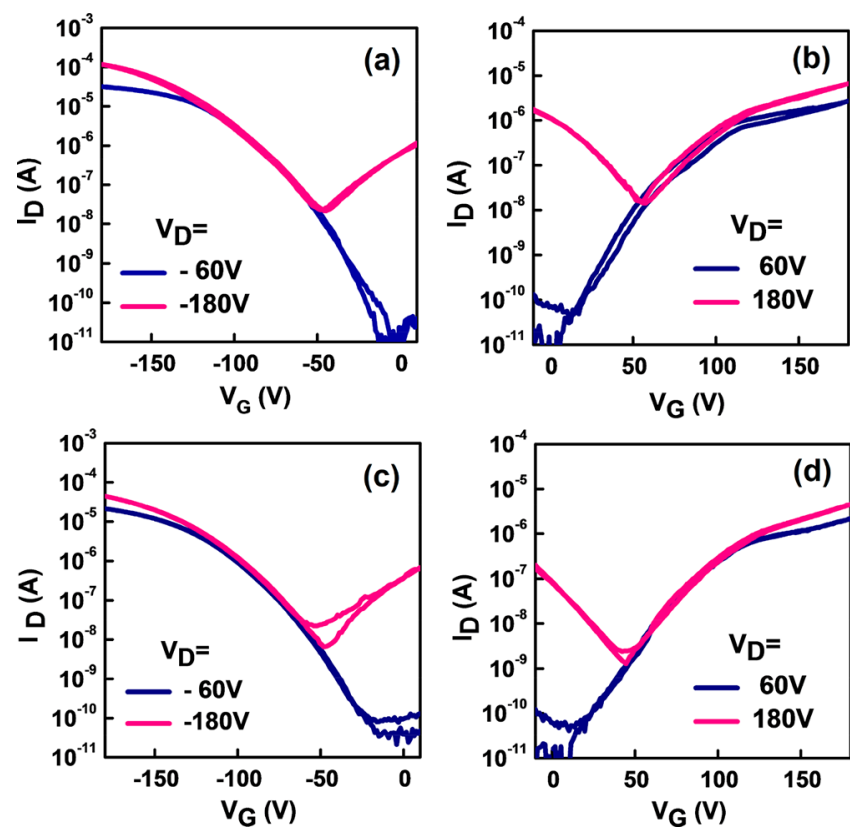

Figure 7. Transfer characteristics for TPE-SeDPP oligomer when annealed at $50{ }^{\circ} \mathrm{C}$ (a and b) and at $100{ }^{\circ} \mathrm{C}$ (c and d). BC-TG TFTs with $\mathrm{Au}$ source-drain electrodes were used for holes (a and $\mathrm{c}$ ), where a bilayer of $\mathrm{Au} / \mathrm{Al}$ for electron charge carriers ( $\mathrm{b}$ and $\mathrm{d}$ ).

and TPE-SeDPP of BC-TG OFETs annealed at 50 and 100 ${ }^{\circ} \mathrm{C}$, in both $\mathrm{p}$ and $\mathrm{n}$-type regime. Both the oligomers show ambipolar charge transport, values of which are presented in Table 3. The charge carrier mobilities $(\mu)$ are evaluated according to gradual-channel approximation in the linear 
Table 3. OFET Characteristics of TPE-TDPP and TPE-SeDPP ${ }^{a}$

\begin{tabular}{|c|c|c|c|c|c|}
\hline \multirow{2}{*}{$\begin{array}{c}\text { molecules } \\
\text { annealing } \\
\text { temperature }\end{array}$} & & \multicolumn{2}{|c|}{ TPE-TDPP } & \multicolumn{2}{|c|}{ TPE-SeDPP } \\
\hline & & $\begin{array}{l}\text { linear mobility } \\
\left(\mathrm{cm}^{2} \mathrm{~V}^{-1} \mathrm{~s}^{-1}\right)^{a}\end{array}$ & $\begin{array}{l}\text { saturation mobility } \\
\left(\mathrm{cm}^{2} \mathrm{~V}^{-1} \mathrm{~s}^{-1}\right)^{a}\end{array}$ & $\begin{array}{l}\text { linear mobility } \\
\left(\mathrm{cm}^{2} \mathrm{~V}^{-1} \mathrm{~s}^{-1}\right)^{a}\end{array}$ & $\begin{array}{l}\text { saturation mobility } \\
\quad\left(\mathrm{cm}^{2} \mathrm{~V}^{-1} \mathrm{~s}^{-1}\right)^{a}\end{array}$ \\
\hline \multirow[t]{2}{*}{$50{ }^{\circ} \mathrm{C}$} & $\mu_{\mathrm{h}}$ & $0.04 \pm 0.01$ & $0.16 \pm 0.04$ & $0.11 \pm 0.03$ & $0.34 \pm 0.04$ \\
\hline & $\mu_{\mathrm{e}}$ & $0.005 \pm 0.003$ & $0.02 \pm 0.03$ & $0.006 \pm 0.002$ & $0.01 \pm 0.006$ \\
\hline \multirow[t]{2}{*}{$100{ }^{\circ} \mathrm{C}$} & $\mu_{\mathrm{h}}$ & $0.07 \pm 0.01$ & $0.26 \pm 0.04$ & $0.07 \pm 0.01$ & $0.13 \pm 0.07$ \\
\hline & $\mu_{\mathrm{e}}$ & $0.10 \pm 0.07$ & $0.12 \pm 0.06$ & $0.007 \pm 0.001$ & $0.012 \pm 0.01$ \\
\hline
\end{tabular}

${ }^{a} \mathrm{Au}$ source-drain electrodes were used to extract hole mobility $\left(\mu_{\mathrm{h}}\right)$ and $\mathrm{Au} / \mathrm{Al}$ to extract electron mobility $\left(\mu_{\mathrm{e}}\right)$.

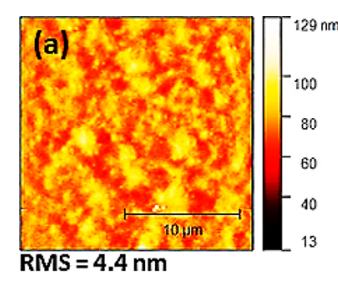

TPE-TDPP AC $(20 \times 20 \mu \mathrm{m})$

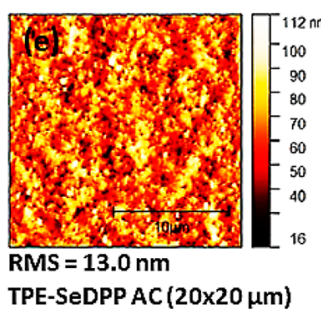

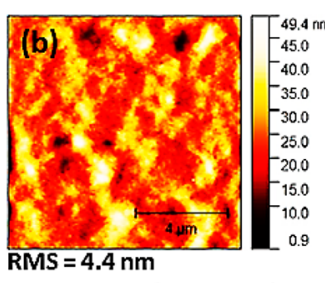

TPE-TDPP AC $(10 \times 10 \mu \mathrm{m})$

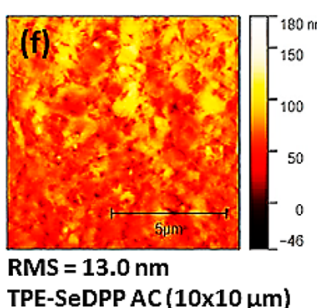

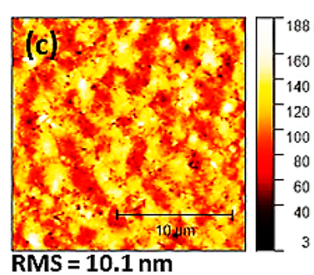

RMS $=10.1 \mathrm{~nm}$
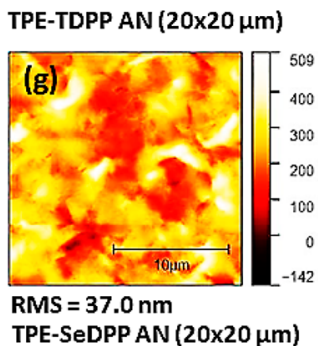

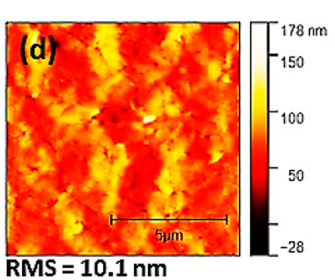

TPE-TDPP AN $(10 \times 10 \mu \mathrm{m})$

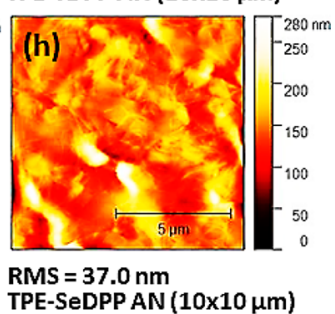

Figure 8. Topographic images obtained by atomic force microscopy (noncontact mode) for TPE-TDPP (a-d) and TPE-SeDPP oligomers (e-h).

regime by $\mu_{1}=L / W C_{\mathrm{i}} V_{\mathrm{D}}\left(\partial \mathrm{I}_{\mathrm{D}} / \partial V_{\mathrm{G}}\right)$ and in the saturation by the $\mu_{\mathrm{s}}=2 L / W C_{\mathrm{i}}\left(\partial \sqrt{I_{\mathrm{D}}} / \partial V_{\mathrm{G}}\right){ }^{2}$ respectively, where $L$ and $W$ are the channel length and width of the devices, $V_{\mathrm{G}}$ is the gate voltage, $C_{\mathrm{i}}$ is the gate dielectric capacitance. The second derivative of the square root of the drain current versus the gate voltage was extracted from their slope. The highest hole mobilities in the linear regimes for TPE-TDPP and TPESeDPP are 0.07 and $0.11 \mathrm{~cm}^{2} \mathrm{~V}^{-1} \mathrm{~s}^{-1}$, respectively. Similarly, the highest electron mobilities in the linear region are 0.10 and $0.007 \mathrm{~cm}^{2} \mathrm{~V}^{-1} \mathrm{~s}^{-1}$ for TPE-TDPP and TPE-SeDPP, respectively (Table 3 ). We attribute the differences in charge carrier mobility between TPE-TDPP and TPE-SeDPP to several parameters including the position of HOMO/LUMO, long-range ordering, and morphological properties. The energetic alignment of the work function of source/drain electrodes with the frontier energy levels of the organic molecules influences the charge injection efficiency with respect to the electrodes being used in OFETs. ${ }^{52}$ In most cases, the hole mobility is higher than the electron mobility (Table 3). This may be attributed to the lower hole injection barrier from the Au electrode (work function $\sim 5.1 \mathrm{eV}$ ) to the HOMO of the semiconductor as compared to the electron injection from the $\mathrm{Al}$ electrode to the LUMO due to its work function and the unavoidable formation of a native oxide layer during device processing.

The output characteristics $\left(I_{\mathrm{D}}\right.$ versus $\left.V_{\mathrm{D}}\right)$ of the devices for TPE-TDPP and TPE-SeDPP are presented in Figures S4 and S5, respectively. The $I_{\mathrm{D}}$ versus $V_{\mathrm{D}}$ curves for both molecules before thermal annealing exhibit a transition from a nonlinear to Ohmic-like behavior at a lower $V_{\mathrm{D}}$ to the saturation characteristic at a higher $V_{\mathrm{D}}$ (Figures S4a,b and S5a,b). This characteristic nonlinearity diminishes upon thermal annealing (Figures S4c,d and S5c,d). However, a pronounced increase in the channel current at low $V_{\mathrm{GS}}$ and high $V_{\mathrm{DS}}$, particularly for the electron accumulation mode, can be observed, which is a characteristic of ambipolar charge transport. ${ }^{53,54}$

Thermal annealing of TPE-TDPP thin film at $100{ }^{\circ} \mathrm{C}$ enhances the charge transport properties. This result is in accordance with the XRD analysis (Figure 5a), which shows dramatic enhancement in crystallinity and microstructural ordering upon annealing the TPE-TDPP layer. Contrary with the TPE-TDPP, annealing TPE-SeDPP thin film at higher temperature $\left(100{ }^{\circ} \mathrm{C}\right)$ does not improve the charge transport, rather there is a nominal decrease in hole mobility after annealing. The electron mobility is not affected by the annealing temperature of the TPE-SeDPP. For TPE-SeDPP, the improvement in microstructural ordering and crystallinity upon annealing is insignificant as compared to the as-cast film, as seen in the XRD results (Figure $5 b$ ). Since in a bottomcontact, top-gate transistor architecture, the semiconductor layer is in direct contact with the gate dielectric, the surface morphology of the organic film is expected to determine the carrier transport across the channel. ${ }^{55,56}$ However, other factors including parasitic contact resistance and formation of grain boundaries may also play an equally important role on the overall performance of the device. ${ }^{57,58}$ Therefore, further investigation of the morphological changes induced upon thermal annealing would be required to understand the reduction in charge carrier mobility.

2.6. Morphological Studies and Thermal Properties. Since, morphological study can provide important insight into the carrier transport mobility of the semiconductor, the surface topographies of TPE-TDPP and TPE-SeDPP films were examined by noncontact mode atomic force microscopy (AFM). As shown in Figure 8a,b, the as cast film of TPETDPP exhibits fine interconnected grain morphology. After 
thermal annealing at $100{ }^{\circ} \mathrm{C}$, significantly larger, welldeveloped, and interconnected crystallites are formed as evident from AFM analysis (Figure $8 \mathrm{c}, \mathrm{d}$ ). The RMS roughness of the film increases from 4.4 to $10.1 \mathrm{~nm}$ upon annealing. The improved density of the grains/domains, better connectivity, and the increased crystallinity are manifested in larger roughness at higher temperature. The thin film XRD study of TPE-TDPP showed that there is a considerable decrease in d-spacing and significant enhancement of intensity of the first order diffraction peak upon annealing (Figure 5a). This implies that for TPE-TDPP, the formation of well-developed aggregates and the increase in roughness after annealing is associated with increased crystallinity and long-range crystal ordering leading to higher mobility in TPE-TDPP after annealing (Table 3).

On the contrary, TPE-SeDPP shows a granular surface morphology with apparent crystalline domains even in the asspun films (Figure 8e,f). The RMS roughness $(13.0 \mathrm{~nm}$ ) is much higher compared to the as cast film of TPE-TDPP implying very coarse surface for TPE-SeDPP. After thermal annealing at $100{ }^{\circ} \mathrm{C}$, it is highly aggregated, and the aggregates are composed of very fine and small fibers (Figure $8 \mathrm{~g}, \mathrm{~h}$ ). The film surface becomes very rough because of aggregate formation, as indicated by the considerably high RMS roughness $(37.0 \mathrm{~nm})$. The formation of interconnected aggregates could be beneficial to the charge transport in OFET devices; however, only up to some threshold values. ${ }^{55,56}$ This is because extensive aggregation and large crystallites can lead to a very rough surface. In top-gated OFET devices, a rough interface between semiconductor and dielectric could result in charge carrier trapping and thus hinder their mobility. For TPE-SeDPP, the improvement in microstructural ordering and crystallinity upon annealing is insignificant as compared to the as cast film, observed from the d-spacing and diffraction peak intensities before and after thermal annealing in the thin film XRD pattern (Figure 5b). The main effect of the thermal annealing is the formation of large aggregates and a very rough surface topography accompanied by a reduction in the charge carrier mobility values for the TPE-SeDPP (Table 3).

In order to gain an insight into the thermal properties of TPE-TDPP and TPE-SeDPP, thermogravimetric analysis (TGA) was carried out under a $\mathrm{N}_{2}$ atmosphere with a heating rate of $5{ }^{\circ} \mathrm{C} \mathrm{min}^{-1}$. Both TPE-TDPP and TPE-SeDPP show onset decomposition temperatures (5\% mass loss) above 350 ${ }^{\circ} \mathrm{C}$, indicating adequate thermal stability over a wide range of temperatures (see Figure S6).

\section{CONCLUSIONS}

Covalent functionalization of the electron deficient TPE core with DPP enables the development of novel ambipolar organic semiconductors. The extracted charge carrier mobilities are moderately high as compared to the previously reported values on star shaped molecules. Optical spectroscopy reveals substantial preaggregation in the solution phase and the existence of J-aggregates in the thin film for both TPE-TDPP and TPE-SeDPP oligomers. The torsional defect in the arms of TPE results in structures, which are intermediate between planar 2D disc shaped and 3D geometries. Both oligomers reveal reversible two electron reductive cycles as well as reversible oxidation processes in cyclic voltammetric analysis. This establishes their ability to stabilize both cations and anions, which is essential for ambipolar charge transport characteristics. Our work proves that judiciously designed star- shaped molecules can be structurally tailored to exhibit comparable ambipolar charge carrier mobility compared to their linear counterparts and can overcome the drawback of anisotropic charge transport associated with linear molecules. Therefore, this work provides future guidelines for judicious backbone and side-chain engineering to induce a higher degree of molecular organization for enhanced charge carrier mobilities.

\section{ASSOCIATED CONTENT}

\section{S Supporting Information}

The Supporting Information is available free of charge on the ACS Publications website at DOI: 10.1021/acsaelm.9b00394.

Materials and methods, experimental procedures, spectral and photophysical characterizations, theoretical methods, and additional transport data (PDF)

\section{AUTHOR INFORMATION}

\section{Corresponding Author}

*E-mail: spatil@iisc.ac.in.

ORCID $\odot$

Thomas D. Anthopoulos: 0000-0002-0978-8813

Satish Patil: 0000-0003-3884-114X

\section{Notes}

The authors declare no competing financial interest.

\section{ACKNOWLEDGMENTS}

S.R. thanks the University Grants Commission (UGC), New Delhi, for Dr. D. S. Kothari's postdoctoral fellowship. S.P. thanks the Department of Science and Technology, New Delhi, India, for a Swarnajayanti fellowship and acknowledges financial support from UKRI Global Challenge Research Fund Project, SUNRISE (Grant EP/P032591/1). We sincerely acknowledge CENSE, IISc for the AFM, GIXRD, and UPS measurements.

\section{REFERENCES}

(1) Yoo, H.; Lee, S. B.; Lee, D. K.; Smits, E. C. P.; Gelinck, G. H.; Cho, K.; Kim, J. J. Top-Split-Gate Ambipolar Organic Thin-Film Transistors. Adv. Electron. Mater. 2018, 4, 1700536.

(2) Tseng, H. R.; Phan, H.; Luo, C.; Wang, M.; Perez, L. A.; Patel, S. N.; Ying, L.; Kramer, E. J.; Nguyen, T. Q.; Bazan, G. C.; Heeger, A. J. High-Mobility Field-Effect Transistors Fabricated with Macroscopic Aligned Semiconducting Polymers. Adv. Mater. 2014, 26, 2993-2998.

(3) Luo, H.; Yu, C.; Liu, Z.; Zhang, G.; Geng, H.; Yi, Y.; Broch, K.; Hu, Y.; Sadhanala, A.; Jiang, L.; Qi, P.; Cai, Z.; Sirringhaus, H.; Zhang, D. Remarkable enhancement of charge carrier mobility of conjugated polymer field-effect transistors upon incorporating an ionic additive. Sci. Adv. 2016, 2, No. e1600076.

(4) Kang, I.; Yun, H. J.; Chung, D. S.; Kwon, S. K.; Kim, Y. H. Record High Hole Mobility in Polymer Semiconductors via SideChain Engineering. J. Am. Chem. Soc. 2013, 135, 14896-14899.

(5) Kim, G.; Kang, S. J.; Dutta, G. K.; Han, Y. K.; Shin, T. J.; Noh, Y. Y.; Yang, C. A Thienoisoindigo-Naphthalene Polymer with Ultrahigh Mobility of $14.4 \mathrm{~cm}^{2} / \mathrm{V} \cdot \mathrm{s}$ That Substantially Exceeds Benchmark Values for Amorphous Silicon Semiconductors. J. Am. Chem. Soc. 2014, 136, 9477-9483.

(6) Paterson, A. F.; Singh, S.; Fallon, K. J.; Hodsden, T.; Han, Y.; Schroeder, B. C.; Bronstein, H.; Heeney, M.; McCulloch, I.; Anthopoulos, T. D. Recent progress in high-mobility organic transistors: a reality check. Adv. Mater. 2018, 30, 1801079.

(7) de Leeuw, D. M.; Simenon, M. M. J.; Brown, A. R.; Einerhand, R. E. F. Stability of n-type doped conducting polymers and 
consequences for polymeric microelectronic devices. Synth. Met. 1997, 87, 53-59.

(8) Di Pietro, R.; Fazzi, D.; Kehoe, T. B.; Sirringhaus, H. Spectroscopic Investigation of Oxygen- and Water-Induced Electron Trapping and Charge Transport Instabilities in n-type Polymer Semiconductors. J. Am. Chem. Soc. 2012, 134, 14877-14889.

(9) Usta, H.; Facchetti, A.; Marks, T. J. n-Channel Semiconductor Materials Design for Organic Complementary Circuits. Acc. Chem. Res. 2011, 44, 501-510.

(10) Zhong, H.; Smith, J.; Rossbauer, S.; White, A. J. P.; Anthopoulos, T. D.; Heeney, M. Air-Stable and High-Mobility nChannel Organic Transistors Based on Small-Molecule/Polymer Semiconducting Blends. Adv. Mater. 2012, 24, 3205-3211.

(11) Gelinck, G.; Heremans, P.; Nomoto, K.; Anthopoulos, T. D. Organic Transistors in Optical Displays and Microelectronic Applications. Adv. Mater. 2010, 22, 3778-3798.

(12) Zhao, X.; Liu, T.; Liu, H.; Wang, S.; Li, X.; Zhang, Y.; Hou, X.; Liu, Z.; Shi, W.; Dennis, T. J. S. Organic Single-Crystalline p-n Heterojunctions for High-Performance Ambipolar Field-Effect Transistors and Broadband Photodetectors. ACS Appl. Mater. Interfaces 2018, 10, 42715-42722.

(13) Nakano, K.; Nakano, M.; Xiao, B.; Zhou, E.; Suzuki, K.; Osaka, I.; Takimiya, K.; Tajima, K. Naphthodithiophene Diimide-Based Copolymers: Ambipolar Semiconductors in Field-Effect Transistors and Electron Acceptors with Near-Infrared Response in Polymer Blend Solar Cells. Macromolecules 2016, 49, 1752-1760.

(14) Wang, R.; Qiao, J.; He, B.; Tang, X.; Wu, F.; Zhu, L. Electron Extraction Layer Based on Diketopyrrolopyrrole/isoindigo to Improve the Efficiency of Inverted Perovskite Solar Cells. J. Mater. Chem. C 2018, 6, 8429-8434.

(15) Sun, B.; Hong, W.; Yan, Z.; Aziz, H.; Li, Y. Record High Electron Mobility of $6.3 \mathrm{~cm}^{2} \mathrm{~V}^{-1} \mathrm{~s}^{-1}$ Achieved for Polymer Semiconductors Using a New Building Block. Adv. Mater. 2014, 26, 26362642.

(16) Chen, Z.; Bird, M.; Lemaur, V.; Radtke, G.; Cornil, J.; Heeney, M.; McCulloch, I.; Sirringhaus, H. Origin of the different transport properties of electron and hole polarons in an ambipolar polyselenophene-based conjugated polymer. Phys. Rev. B: Condens. Matter Mater. Phys. 2011, 84, 115211.

(17) Chang, J. F.; Sirringhaus, H.; Giles, M.; Heeney, M.; McCulloch, I. Relative importance of polaron activation and disorder on charge transport in high-mobility conjugated polymer field-effect transistors. Phys. Rev. B: Condens. Matter Mater. Phys. 2007, 76, 205204.

(18) Kang, W.; Jung, M.; Cha, W.; Jang, S.; Yoon, Y.; Kim, H.; Son, H. J.; Lee, D. K.; Kim, B. S.; Cho, J. H. High Crystalline Dithienosilole-Cored Small Molecule Semiconductor for Ambipolar Transistor and Nonvolatile Memory. ACS Appl. Mater. Interfaces 2014, 6, 6589-6597.

(19) Wu, S. L.; Huang, Y. F.; Hsieh, C. T.; Lai, B. H.; Tseng, P. S.; Ou, J. T.; Liao, S. T.; Chou, S. Y.; Wu, K. Y.; Wang, C. L. Roles of 3Ethylrhodanine in Attaining Highly Ordered Crystal Arrays of Ambipolar Diketopyrrolopyrrole Oligomers. ACS Appl. Mater. Interfaces 2017, 9, 14967-14973.

(20) Dhar, J.; Mukhopadhay, T.; Yaacobi-Gross, N.; Anthopoulos, T. D.; Salzner, U.; Swaraj, S.; Patil, S. Effect of Chalcogens on Electronic and Photophysical Properties of Vinylene-Based Diketopyrrolopyrrole Copolymers. J. Phys. Chem. B 2015, 119, 1130711316.

(21) Mukhopadhyay, T.; Puttaraju, B.; Senanayak, S. P.; Sadhanala, A.; Friend, R.; Faber, H. A.; Anthopoulos, T. D.; Salzner, U.; Meyer, A.; Patil, S. Air-Stable n-channel Diketopyrrolopyrrole-Diketopyrrolopyrrole Oligomers for High Performance Ambipolar Organic Transistors. ACS Appl. Mater. Interfaces 2016, 8, 25415-25427.

(22) Zhu, J.; Wang, W.; Zhong, Q.; Li, L.; Du, C.; Lv, A.; Wang, H.; Fuchs, H.; Chi, L. Patterning rubrene crystalline thin films for submicrometer channel length field-effect transistor arrays. J. Mater. Chem. C 2014, 2, 9359-9363.
(23) Xie, W.; Prabhumirashi, P. L.; Nakayama, Y.; McGarry, K. A.; Geier, M. L.; Uragami, Y.; Mase, K.; Douglas, C. J.; Ishii, H.; Hersam, M. C.; Frisbie, C. D. Utilizing Carbon Nanotube Electrodes to Improve Charge Injection and Transport in Bis(trifluoromethyl)dimethyl-rubrene Ambipolar Single Crystal Transistors. ACS Nano 2013, 7, 10245-10256.

(24) Wan, S.; Gandara, F.; Asano, A.; Furukawa, H.; Saeki, A.; Dey, S. K.; Liao, L.; Ambrogio, M. W.; Botros, Y. Y.; Duan, X.; Seki, S.; Stoddart, J. F.; Yaghi, O. M. Covalent Organic Frameworks with High Charge Carrier Mobility. Chem. Mater. 2011, 23, 4094-4097.

(25) Ren, J. M.; McKenzie, T. G.; Fu, Q.; Wong, E. H. H.; Xu, J.; An, Z.; Shanmugam, S.; Davis, T. P.; Boyer, C.; Qiao, G. G. Star Polymers. Chem. Rev. 2016, 116, 6743-6836.

(26) Kanibolotsky, A. L.; Perepichka, I. F.; Skabara, P. J. Star-shaped p-conjugated oligomers and their applications in organic electronics and photonics. Chem. Soc. Rev. 2010, 39, 2695-2728.

(27) Roncali, J.; Leriche, P.; Cravino, A. From One- to ThreeDimensional Organic Semiconductors: In Search of the Organic Silicon? Adv. Mater. 2007, 19, 2045-2060.

(28) Lin, Y.; Wang, Y.; Wang, J.; Hou, J.; Li, Y.; Zhu, D.; Zhan, X. A Star-Shaped Perylene Diimide Electron Acceptor for High-Performance Organic Solar Cells. Adv. Mater. 2014, 26, 5137-5142.

(29) Lin, Y.; Cheng, P.; Li, Y.; Zhan, X. A 3D star-shaped nonfullerene acceptor for solution-processed organic solar cells with a high open-circuit voltage of 1.18 V. Chem. Commun. 2012, 48, 47734775 .

(30) Sun, Y.; Xiao, K.; Liu, Y.; Wang, J.; Pei, J.; Yu, G.; Zhu, D. Oligothiophene-Functionalized Truxene: Star-Shaped Compounds for Organic Field-Effect Transistors. Adv. Funct. Mater. 2005, 15, $818-822$.

(31) Li, S.; Liu, W.; Shi, M.; Mai, J.; Lau, T. K.; Wan, J.; Lu, X.; Li, C. Z.; Chen, H. A spirobifluorene and diketopyrrolopyrrole moieties based non-fullerene acceptor for efficient and thermally stable polymer solar cells with high open-circuit voltage. Energy Environ. Sci. 2016, 9, 604-610.

(32) Ponomarenko, S. A.; Kirchmeyer, S.; Elschner, A.; Huisman, B. H.; Karbach, A.; Drechsler, D. Star-Shaped Oligothiophenes for Solution-Processible Organic Field-Effect Transistors. Adv. Funct. Mater. 2003, 13, 591-596.

(33) Zhang, Y.; Chen, L.; Zhang, K.; Wang, H.; Xiao, Y. A Soluble Ladder-Conjugated Star-Shaped Oligomer Composed of Four Perylene Diimide Branches and a Fluorene Core: Synthesis and Properties. Chem. - Eur. J. 2014, 20, 10170-10178.

(34) Liu, S.-Y.; Liu, W.-Q.; Xu, J.-Q.; Fan, C. C.; Fu, W.-F.; Ling, J.; Wu, J.-Y.; Shi, M.-M.; Jen, A. K.-Y.; Chen, H.-Z. Pyrene and Diketopyrrolopyrrole-Based Oligomers Synthesized via Direct Arylation for OSC Applications. ACS Appl. Mater. Interfaces 2014, 6, 6765-6775.

(35) He, Q.; Shahid, M.; Panidi, J.; Marsh, A. V.; Huang, W.; Daboczi, M.; Kim, J. S.; Fei, Z.; Anthopoulos, T. D.; Heeney, M. A versatile star-shaped organic semiconductor based on benzodithiophene and diketopyrrolopyrrole. J. Mater. Chem. C 2019, 7, 66226629.

(36) Liu, S.-Y.; Liu, W.-Q.; Yuan, C.-X.; Zhong, A.-G.; Han, D.; Wang, B.; Shah, M.; Shi, M.-M.; Chen, H. DiketopyrrolopyrroleBased Oligomers Accessed via Sequential $\mathrm{CH}$ Activated Coupling for Fullerene-Free Organic Photovoltaics. Dyes Pigm. 2016, 134, 139147.

(37) Sun, P.; Sun, H.; Li, X.; Wang, Y.; Shan, H.; Xu, J.; Zhang, C.; $\mathrm{Xu}, \mathrm{Z}$.; Chen, Z.-K.; Huang, W. Three Dimensional Multi-Arm Acceptors Based on Diketopyrrolopyrrole with (hetero)aromatic Cores for Non-Fullerene Organic Solar Cells without Additional Treatment. Dyes Pigm. 2017, 139, 412-419.

(38) Liu, S.-Y.; Wang, D.-G.; Zhong, A.-G.; Wen, H.-R. One-Step Rapid Synthesis of $\Pi$-Conjugated Large Oligomers via $\mathrm{C}-\mathrm{H}$ Activation Coupling. Org. Chem. Front. 2018, 5, 653-661.

(39) Rananaware, A.; Gupta, A.; Li, J.; Bilic, A.; Jones, L.; Bhargava, S.; Bhosale, S. A Four-Directional Non-Fullerene Acceptor Based on Tetraphenylethylene and Diketopyrrolopyrrole Functionalities for 
Efficient Photovoltaic Devices with a High Open-Circuit Voltage of 1.18 V. Chem. Commun. 2016, 52, 8522-8525.

(40) Chen, Q.; Wang, J. X.; Yang, F.; Zhou, D.; Bian, N.; Zhang, X. J.; Yan, C. G.; Han, B. H. Tetraphenylethylene-based fluorescent porous organic polymers: preparation, gas sorption properties and photoluminescence properties. J. Mater. Chem. 2011, 21, 1355413560 .

(41) Pickett, A.; Torkkeli, M.; Mukhopadhyay, T.; Puttaraju, B.; Laudari, A.; Lauritzen, A.; Bikondoa, O.; Kjelstrup-Hansen, J.; Knaapila, M.; Patil, S.; Guha, S. Correlating Charge Transport with Structure in Deconstructed Diketopyrrolopyrrole Oligomers: A Case Study of a Monomer in Field-Effect Transistors. ACS Appl. Mater. Interfaces 2018, 10, 19844-19852.

(42) Spano, F. C.; Silva, C. H- and J-Aggregate Behavior in Polymeric Semiconductors. Annu. Rev. Phys. Chem. 2014, 65, 477500.

(43) Spano, F. C. The Spectral Signatures of Frenkel Polarons in Hand J-Aggregates. Acc. Chem. Res. 2010, 43, 429-439.

(44) Chowdhury, A.; Wachsmann-Hogiu, S.; Bangal, P. R.; Raheem, I.; Peteanu, L. A. Characterization of Chiral $\mathrm{H}$ and J Aggregates of Cyanine Dyes Formed by DNA Templating Using Stark and Fluorescence Spectroscopies. J. Phys. Chem. B 2001, 105, 1219612201.

(45) Más-Montoya, M.; Janssen, R. A. J. The Effect of H- and JAggregation on the Photophysical and Photovoltaic Properties of Small Thiophene-Pyridine-DPP Molecules for Bulk-Heterojunction Solar Cells. Adv. Funct. Mater. 2017, 27, 1605779.

(46) DeLongchamp, D. M.; Vogel, B. M.; Jung, Y.; Gurau, M. C.; Richter, C. A.; Kirillov, O. A.; Obrzut, J.; Fischer, D. A.; Sambasivan, S.; Richter, L. J.; Lin, E. K. Variations in Semiconducting Polymer Microstructure and Hole Mobility with Spin-Coating Speed. Chem. Mater. 2005, 17, 5610-5612.

(47) Dhar, J.; Venkatramaiah, N.; Anitha, A.; Patil, S. Photophysical, electrochemical and solid state properties of diketopyrrolopyrrole based molecular materials: importance of the donor group. J. Mater. Chem. C 2014, 2, 3457-3466.

(48) Bleiholder, C.; Gleiter, R.; Werz, D. B.; Köppel, H. Theoretical Investigations on Heteronuclear Chalcogen-Chalcogen Interactions: On the Nature of Weak Bonds between Chalcogen Centers. Inorg. Chem. 2007, 46, 2249-2260.

(49) Shahid, M.; McCarthy-Ward, T.; Labram, J.; Rossbauer, S.; Domingo, E. B.; Watkins, S. E.; Stingelin, N.; Anthopoulos, T. D.; Heeney, M. Low band gap selenophene-diketopyrrolopyrrole polymers exhibiting high and balanced ambipolar performance in bottom-gate transistors. Chem. Sci. 2012, 3, 181-185.

(50) Chen, H. Y.; Nikolka, M.; Wadsworth, A.; Yue, W.; Onwubiko, A.; Xiao, M.; White, A. J. P.; Baran, D.; Sirringhaus, H.; McCulloch, I. A Thieno[2,3-b]pyridine-Flanked Diketopyrrolopyrrole Polymer as an n-Type Polymer Semiconductor for All-Polymer Solar Cells and Organic Field-Effect Transistors. Macromolecules 2018, 51, 71-79.

(51) Dickey, K. C.; Anthony, J. E.; Loo, Y. L. Improving Organic Thin-Film Transistor Performance through Solvent-Vapor Annealing of Solution-Processable Triethylsilylethynyl Anthradithiophene. Adv. Mater. 2006, 18, 1721-1726.

(52) Kumatani, A.; Li, Y.; Darmawan, P.; Minari, T.; Tsukagoshi, K. On Practical Charge Injection at the Metal/Organic Semiconductor Interface. Sci. Rep. 2013, 3, 1026.

(53) Bura, T.; Beaupre, S.; Ibraikulov, O. A.; Legare, M.-A.; Quinn, J.; Leveque, P.; Heiser, T.; Li, Y.; Leclerc, N.; Leclerc, M. New Fluorinated Dithienyldiketopyrrolopyrrole Monomers and Polymers for Organic Electronics. Macromolecules 2017, 50, 7080-7090.

(54) Smits, E. C. P.; Anthopoulos, T. D.; Setayesh, S.; van Veenendaal, E.; Coehoorn, R.; Blom, P. W. M.; de Boer, B.; de Leeuw, D. M. Ambipolar charge transport in organic field-effect transistors. Phys. Rev. B: Condens. Matter Mater. Phys. 2006, 73, 205316-205324.

(55) Kim, M. J.; Jung, A. R.; Lee, M.; Kim, D.; Ro, S.; Jin, S. M.; Nguyen, H. D.; Yang, J.; Lee, K. K.; Lee, E.; Kang, M. S.; Kim, H.; Choi, J. H.; Kim, B. S.; Cho, J. H. Structure-Property Relationships of
Semiconducting Polymers for Flexible and Durable Polymer FieldEffect Transistors. ACS Appl. Mater. Interfaces 2017, 9, 40503-40515.

(56) Opoku, H.; Nketia-Yawson, B.; Shin, E.-S.; Noh, Y.-Y. Organic field-effect transistors processed by an environmentally friendly nonhalogenated solvent blend. J. Mater. Chem. C 2018, 6, 661-667.

(57) Paterson, A. F.; Anthopoulos, T. D. Enabling thin-film transistor technologies and the device metrics that matter. Nat. Commun. 2018, 9, 5264.

(58) Salleo, A. Charge transport in polymeric transistors. Mater. Today 2007, 10, 38-45. 